\title{
Sustainable Supply Chain Based Scenarios for Optimizing Trade-off between Indonesian Furniture and Crude-Palm-Oil Industries
}

\author{
Kuncoro Harto Widodo \\ Dept. of Agriculture Industrial Technology, Faculty of Agricultural Technology, Universitas Gadjah Mada, \\ Center for Transportation and Logistics Studies, Universitas Gadjah Mada, \\ Bulaksumur. 55281. Yogyakarta, Indonesia \\ Email address: kuncorohw@ugm.ac.id
}

\begin{abstract}
Trade-off, as the consequences of using the same resources, often occurs in the development of two or more business activities, e.g. between the supply chain of Indonesian furniture and crude-palm-oil (CPO) industries. The two industries use the land area to get supply of raw material. The furniture industries need wide area of forest to obtain an adequate wood supply while the CPO industries need wide land area to open new palm plantations. The previous research has identified the relationship of the two industries and the trade-off between them using a dynamic model approach. This research aims to modify the model and to propose some scenarios that may optimize the trade-off based on the previous results. We provide scenarios based on the development policy of Indonesian government. The scenarios are simulated using the modified of dynamic model. We obtain that the best scenario is scenario 3 which can optimize the trade-off between the supply chain of furniture and CPO industries in line with long term sustainable development. The scenario is set by increasing the productivity of palm plantations to change the pattern from extension into intensification by using robust palm plants.
\end{abstract}

Keywords: dynamic model, sustainable development, supply chain, furniture, CPO.

\section{Introduction}

Indonesian industries, e.g. furniture and Crude-PalmOil (CPO) industries, have a very big contribution to the economy of Indonesia. The Indonesian furniture industry is the $12^{\text {th }}$ and the CPO industry is the $1^{\text {st }}$ in the world now (The Ministry of Industry Republic of Indonesia, 2008). They grow because of the Indonesian wealth in natural resources. Forest provides woods and other raw materials for producing furniture, while palm plantations supply material for $\mathrm{CPO}$ industries.

According to the Directorate General of Estate Crops, Ministry of Agriculture Republic of Indonesia (2008), CPO industry is an industry that provides a strategic product that are used as a substance of food (cooking oil) and as an alternative bio-fuel. The data shows that the amount of Indonesian CPO production increases during 1990s until 2000s. From the CPO production, $75 \%$ is for export and $25 \%$ is for domestic consumption. Domestic demand is very high and tends to raise so that government has to make regulations to cope with this problem. CPO is the most traded vegetable oil in the world, capturing $40 \%$ of global trade. Palm oil, in majority (more than $84 \%$ ), is produced in Southeast Asia. Indonesia provides almost $30 \%$ of world production and exports $60 \%$ of the annual CPO production. 
The Indonesian export of furniture products are dominated by furniture products made from forest woods $(75 \%)$ and the rest $(25 \%)$ are made from cane and other raw materials. These give currency contribution up to $1.64 \%$ (Tambunan, 2006). Therefore, furniture industries, generally called woods industry, are one of pre-eminent industries in Indonesia. Its development, however, were decreasing in the few years. Based on the data from Indonesia Statistics (2006), in the last three years Indonesian wood products had a negative growth in the rate of $-2.1 \%,-1.3 \%$, and $-5.8 \%$ in 2004,2005 , and 2006, respectively. Export of Indonesian furniture products has been growing up to 1.79 billion dollar US or, in other words, the growth rate is up to 0.088 billion dollar US per year in the last eight years. In the same period, China, a country that has a relative tight policy in using the woods, could export furniture products up to 14 billion dollar US in 2005, and that the export rate has been growing up to 1.1 billion dollar US per year.

The decreasing number of furniture production, especially, is affected by the decrease of wood availability as the raw material, because of the destruction of Indonesian forest. The destruction of forest is due to various activities, one of them is the opening of palm plantation, which becomes the attention of the world. While, the production of CPO in Indonesia has been increasing in the few years and it is balanced with increasing width of palm plantation. The negative impact for the environment becomes more serious because the increase of palm plantation width affects to environment. One of those effects is deforestation because the enlargement of palm plantation takes place of forest area (Widodo et al., 2009a).

Widodo et al. (2009c) proposed a dynamic model for analyzing trade-off between the supply chain of furniture and $\mathrm{CPO}$ industries and for analyzing the interaction between them in exploiting forest resources by considering sustainable development. The research has identified the relationship of the two industries and the trade-off between them using a dynamic model approach. They, however, did not provide solution to deal with the impact of some condition for the trade-off. In this research, therefore, we propose scenarios to optimize trade-off between the two industries by modifying the dynamic model.
We provide scenarios based on the development plans of the Indonesian Government. The scenarios are simulated using the modified dynamic model.

\section{Literature Review}

Beamon (2008) proposed that global supply chain has entered new era in challenge and opportunities. Environment protection, energy availability, and population growth create pressure that has never happened before. Those challenges demand for supply chain ability to raise efficiency and effectiveness in providing goods and services. Environmental protection, gradually, becomes real issue for manufacturer in developing their product. The companies' support to green supply chain development is very important to increase the industries' performance (Lin et al., 2008). Environmental issue has become an important global issue in recent years. The issue has been more appreciated since it is related with the increase of population and how industries affect environment. Industry needs to concern on environmental impact of business activities besides economic profit (Eltayeb et al., 2009).

Some researches deal with furniture and $\mathrm{CPO}$ industries, however, they tend to consider primary on the profit from the perspective of operational management and see it as a single industry so that there is no trade-off occurs. Vickery et al. (1997), proposed four factors which affect the competitive advantage of any furniture industry: inovation, flexibility, value and delivery. Robb et al. (2008), focused their research on the relationships between operations and supply chain within operasional or financial performance of China furniture industry. Johar et al. (2003) and Rika and Machfud (2008), provided a system analysis for CPO supply chain to improve its competitive advantage.

The concept of sustainable has been considered in the development of many activites, either in the economical or non-economical (non-profitable) activities. De Lara and Martinet (2009) discussed that sustainable resources management is a hard duty, as the impact of the dynamism, uncertainty, and various objectives (ecology, economic, dan social). Widodo et al. (2009c) proposed that the development of industries, especially agro- 
industries and forest-industries, needs more than just considering how to get the biggest profit. It should also concern with social and environmental aspects. These points of view are very important in order to develop sustainable industry.

Sustainable within the concept of supply chain becomes more interesting for practicioners and academicians (Bovea and Vidal, 2004; Linton et al., 2007; Ortiz et al., 2009; Widodo et al.,2009a; Widodo et al.,2009b; Widodo et al.,2009c and Widodo et al., 2009d). In this case, dynamic model is a suitable tool for analyzing such a complex system. There are some papers illustrated the implementation of a dynamic model and a dynamic simulation (Lee et al., 2002; Min and Zhou, 2002; Terzi and Cavalieri, 2003; Fleisch and Tellkamp, 2005; Schwartz et al., 2006; Jammernegga and Reiner, 2007; Pierreval et al., 2007; Longo and Mirabelli, 2008 and Lau et al., 2008). Min and Zhou (2002) provided how the development of modeling and simulation up to now, identify opportunity and challenge in supply chain modeling, and gave a guidance on how to be succeed in developing and applicating supply chain modeling. Boulanger and Bre'chet (2005) proposed how to measure up the strength and weakness of the model made by the decision maker related to the impact in sustainable development perspective. The two policies they measure up are the policies that related to energy problem and land usage related to transportation plan. Almost all these papers, however, are not interested in analyzing the integration or the trade-off between industries and considering the aspects of environment and social within the context of sustainable development.

\section{Entities in the Furniture and CPO Supply Chain}

Supply chain of furniture and CPO industries is described using the identification of the previous research (Widodo et al., 2009c). Entities of the supply chain of CPO industry are defined below.

1. Supplier of palm consists of $2,565,000$ ha smallholder palm plantation estate $(38.7 \%$ of the national palm plantation), 687,000 ha state plantation (10.3\% of the national palm plantation), and $3,358,000$ ha private palm plantation $(50.7 \%$ of the national palm plantation).
2. $\mathrm{CPO}$ producer is a company that produces $\mathrm{CPO}$ from palm plantation. CPO producer consists of state, smallholder estate, and private companies. From the total production of 15.120.644 tones in 2008, state, smallholder, and private companies produce $13.6 \%, 38.8 \%$, and $47.5 \%$, respectively.

3. Consumers of $\mathrm{CPO}$ are industries that process $\mathrm{CPO}$ into different products. Consumers are divided into 2 types as follows.

a. Domestic industries

They consume $\mathrm{CPO}$ as a raw material for their products. These industries include cooking oil, bio-energy, food and beverage, and cosmetic industries. Directorate General of Estate Crops, Ministry of Agriculture Republic of Indonesia (2008) reported that $40 \%$ of the total product is allocated for domestic consumption.

b. Foreign industries

The export of CPO reached 350,000 tones and increased up to 9.6 million in 2004. India, China, Nederland and Singapore are the main market. The amount of export in 2008 was $60 \%$ of the total production.

Supply chain entities of furniture industry are defined below.

1. Furniture industries need forest woods to produce furniture products. Consumption of forest wood for furniture industries is up to 7 7.5 million $\mathrm{m}^{3}$ per years. But, in the couple of years, the woods had been imported. It keeps on increasing during the years. The type of forest woods used in this industry is log which is obtained from natural forest, conversion forest, industrial forest plantation, etc.

2. The forest wood then is used to produce furniture products at the center of furniture and craft industries in Java, Sumatra, Kalimantan and Sulawesi Islands. The forest wood is not just used as a raw material in furniture industry but also used for plywood, pulp, and other industries. It forces them to compete with each other to get the woods. Now, in Indonesia, there are 950 units of furniture industries and they consume 3.41 million $\mathrm{m} 3$ woods per year.

3. Most of the Indonesian furniture products are exported. The rest are sold for domestic markets in the amount of $31,939 \mathrm{~m}^{3}$ annually. 


\section{Model Development and Simulation}

\subsection{Initial Model}

Widodo et al. (2009c) proposed a dynamic model for analyzing trade-off between the supply chain of furniture and CPO industries and the interaction between them in exploiting forest resources by considering sustainable development. The research has identified the correlation between the supply chain of furniture and CPO industries in using land resources. The correlation and the trade-off between the two industries are described using causal loop as shown in Figure 1.

Furniture demand affects wood demand as an impact of the increase of production activity. This high demand also affects hewing activity. While in CPO industries, the increase of population contributes to the raise of CPO demand. In turn, the need of palm supply also grows. It may results in the opening new palm plantations. In causal loop, furniture and $\mathrm{CPO}$ industries are connected by the commonality in the contribution of production forest width. Both palm plantation opening and forest hewing affect the production forest width, and finally it will affect wood production and palm plantation width.

\subsection{Dynamic Model Development and Validation}

Causal loop in Figure 1 consists of elements of supply chain in the furniture and CPO industries which have a causal relationship. The relationship among the elements are positive $(+)$ and negative $(-)$. The positive means that if one element in the causal loop is improved it will increase another element, or if one element is decreased then another element is also decreased. On the other hand, the negative means that if one element is increased, it will decrease another element and vice versa.

Based on the identification of supply chain entities of both industries and the relationships between them (in the causal loop), we formulate dynamic model by modifying the previous one

Figure 1. Causal Loop of the Relationships between Furniture and CPO Industries

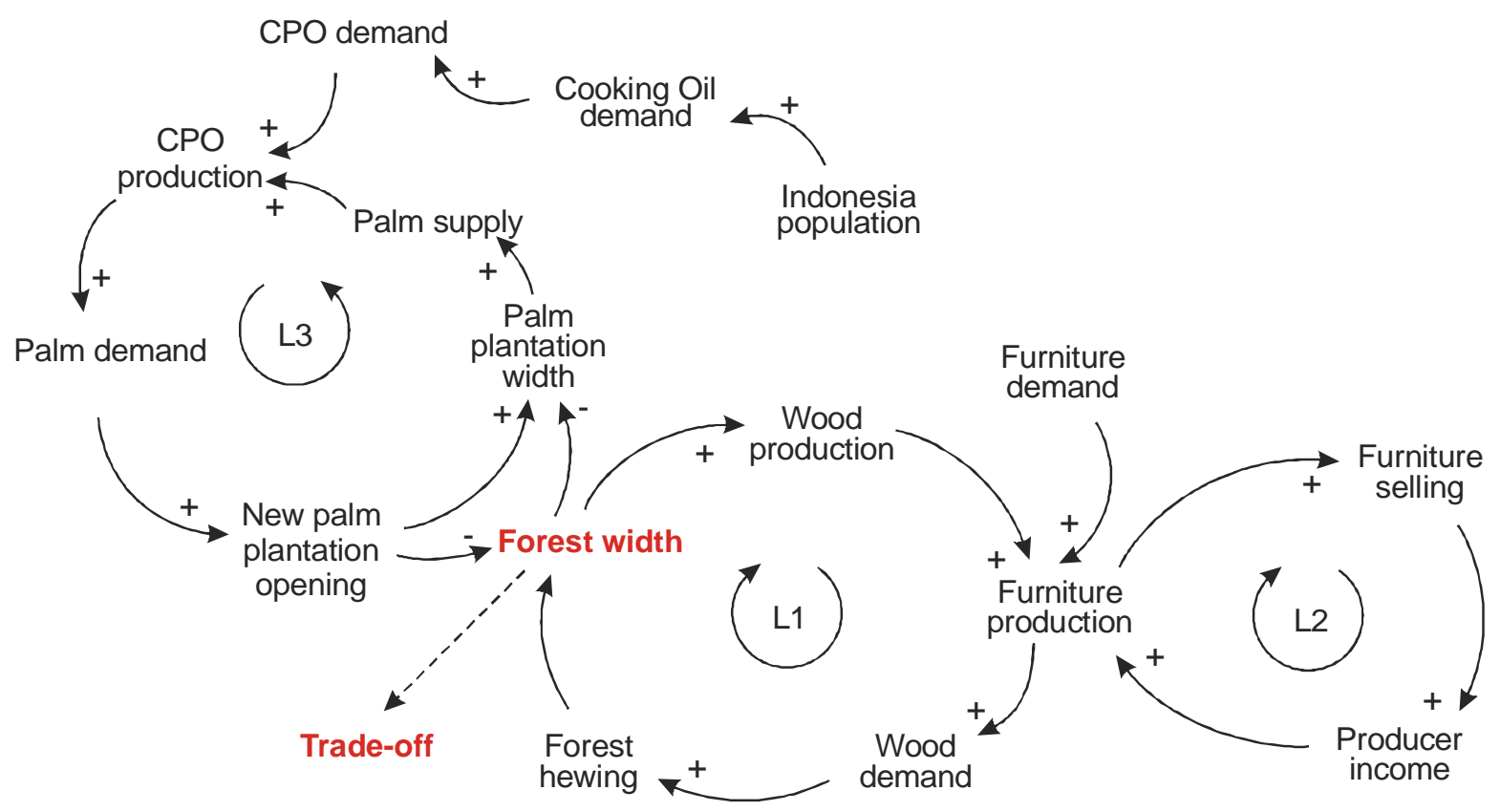


(Widodo et al., 2009c) as illustrated in Figure 2. The model consists of two independent submodels: furniture industry and CPO industry. These two sub-models are linked by their similarity to obtain raw material from the same land.

Furniture industries get woods from forest area while CPO industries need land to open new palm plantations. However, they do not need to open it if the existing palm plantations are sufficient to supply the demand. To open new plantations, the industries tend to open forest area. Therefore, there would be a trade-off between the two industries especially when they compete in deriving land area for supplying raw materials. Model in Figure 2 describes the trade-off for predicting the future condition and for illustrating the relationships between the sub-model and their behaviour.

Validation analysis has been carried out for both of the sub-models to check the logical relationship between elements using extreme condition and independent-sample $t$ test method. Validation of furniture industries sub-model was analyzed using extreme condition method because the available data was not sufficient for statistic parametric analysis. The zero demand of furniture product was used as an extreme condition. By inputting 0 values to variable demand in the model, the income of furniture industries becomes 0 because there is no product available to sell. This result shows that the logical thinking used in furniture industries' sub model is valid.

We used independent-sample $t$ test to analyze the validation of CPO industries' sub model because the time series data was available for using statistic parametric method. The test was applied to check the significance of different mean between actual data and simulation result. The amount of production in years 1990-2007 and the amount of the next 15 years simulation result were used as samples. The samples then were tested with validation analysis. The result shows that the variant of those samples is not different for the significance value is 0.48 (more than $\alpha=0.05$ ). We, therefore, conclude that the sub model of CPO industries is valid.

\subsection{Simulation}

\subsubsection{Simulation using initial model}

The simulation using initial model showed that there is a different demand pattern between furniture and CPO industries. Furniture demand tends to be uncertain but relatively constant because the consumption or the use period of these products is relatively long. The growing number of population does not affect the industry signicantly.

CPO demand, however, tends to raise significantly because of the increasing number of both domestic and foreign demand. In case of domestic demand, its growth is influenced primarily by the population growth. It happens because the main derivative of $\mathrm{CPO}$ is cooking oil which is a fast product consumption. Indonesian consumption of cooking oil is $9 \mathrm{kgs} /$ year and $13.5 \mathrm{kgs} / y e a r$ for CPO. In case of foreign demand, however, it is fluctuative.

Deforestation and the opening of new palm plantations become evidences of the impact of furniture and CPO industries activities. The simulation results showed that the need of palm plantations area is growing and that the demand of plantation lands is answered by deforestation. This condition would reduce the widht of production-forest. Other factor that may contribute to the problem is forestry ilegal activities such as forest resources exploration. As a result, within the initial condition, productionforest will still available until the next 17 years while the width of palm plantation is still growing.

From other perspective, the opening of new palm plantation would provide many job opportunities. Now, there are 6 million ha plantations, with 1 labor per ha. Hence, there are 6 million labors are absorbed. The increase of the plantation width, therefore, gives a positive impact and linear to the absorption of labor.

\subsubsection{Simulation using scenarios}

We propose scenarios to be applied in the model for selecting the best scenario for optimizing the tradeoff between furniture and CPO industries based on strategies and policies of the Government of the Republic of Indonesia (Road Map of Forestry 
Table 1. Three scenarios for optimizing the trade- off between furniture and CPO industries

\begin{tabular}{|c|c|c|}
\hline \multicolumn{1}{|c|}{ Scenario 1 } & \multicolumn{1}{|c|}{ Scenario 2 } & Scenario3 \\
\hline $\begin{array}{l}\text { 1. It is conducted in sub model of furniture } \\
\text { industry. }\end{array}$ & $\begin{array}{l}\text { 1. It is implemented in sub model of } \\
\text { furniture industry. }\end{array}$ & 1. It is applied in sub model of CPO industry. \\
\hline $\begin{array}{l}\text { 2. It is set by increasing legal wood supply. } \\
\text { It is obtained by increasing } 10 \% \text { annually } \\
\text { production of natural production forest } \\
\text { and by realizing the target of Indonesian } \\
\text { government to plant } 75 \text { thousand ha of } \\
\text { industrial forest plantations. }\end{array}$ & $\begin{array}{l}\text { 2. It is formulated by increasing the furniture } \\
\text { industries utilization from } 64 \% \text { in the } \\
\text { existing condition to more than } 70 \% \\
\text { according to The Indonesian Government } \\
\text { policy. }\end{array}$ & $\begin{array}{l}\text { 2. It is designed by increasing the } \\
\text { productivity of palm plantations to } \\
\text { obtain7-8 ton/ ha/ year CPO. }\end{array}$ \\
\hline
\end{tabular}

Figure 2. Dynamic Model of Furniture and CPO industries

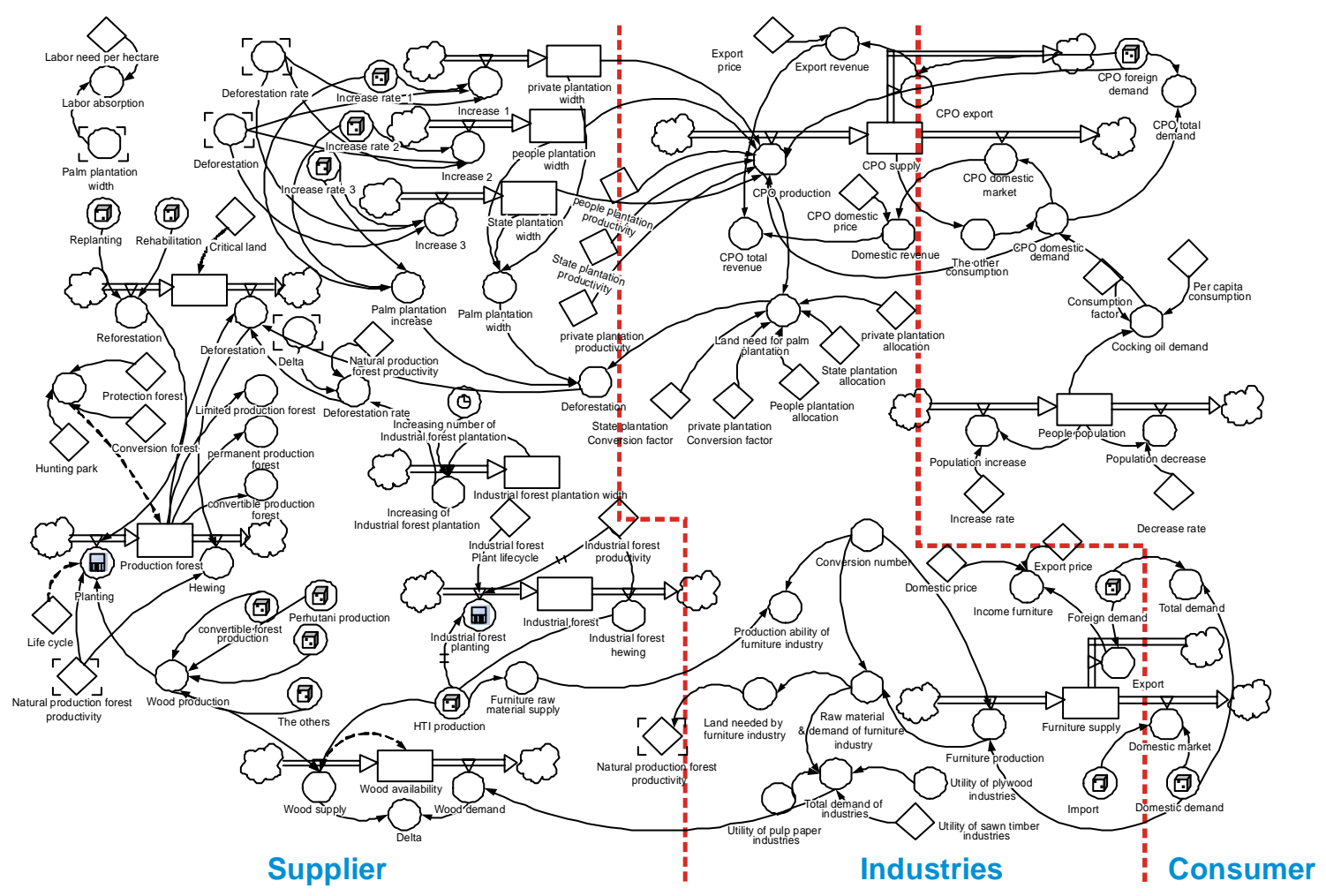

Industry Revitalization, Forestry Department of the Republic of Indonesia, 2007, and the Report of Manufacture Industry Development of Industrial Department of the Republic of Indonesia, 2008). There are 3 scenarios, scenario 1 and 2 are based on sub-model of furniture industry while scenario 3 is based on sub-model of CPO industry as described in Table 1.

\section{Simulation Results and Analysis}

\subsection{Trade-off between palm plantation and production forest width development}

The relationships between opening the new palm plantations and CPO industry development is important to be considered because it may critical to 
the availability of production forest existence. Production forest protects environmental condition and guarantees the existence and continuity of furniture industry and the other forestry industries as well. A distinctive difference appears in the land needed by the two industries. The CPO needs larger land area to get raw material supply than the furniture.

The trade-off that may occur in furniture and $\mathrm{CPO}$ industries development is between forest production existence and the growth of palm plantation width. Using the formulated scenarios, we can find the influence to the trade-off. Figure 3 shows the trade-off changes along with the application of the scenarios. In scenario 1, the improvement of forest management to increase raw material supply for industry may reduce the decrease rate of natural production forest so it can exist up to the next 22 years. Availability of wood supply for industry will reduce the demand of illegal wood so that uncontrolled hewing could be minimized. On the other hand, however, the development of palm plantation boosts because there are available land to open new palm plantations.

The increase of production capacity of furniture industry as formulated in scenario 2 contributes to the decrease of forest area if it does not followed by the improvement in forest management. The availability of forest area gives possibility to the increase of palm plantations area. Figure 3 shows that some values drop (for existing condition, scenario 1 and scenario 2) to a negative level. Negative value means that Indonesian does not have production forest anymore and should get the woods from other

Figure 3. The Trade-off in Development of Palm Plantation Width and Forest Production Width at All of Scenarios

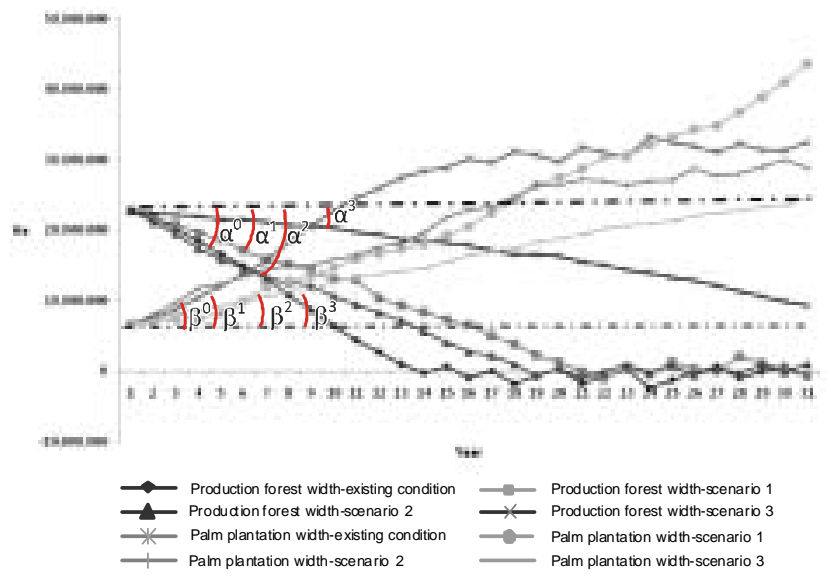

kinds of forest. Figure 3 also shows condition in the next 15 years in which production forest would be lost and at that time there is no increasing of palm plantation width.

The application of scenario 3 makes palm plantation development becomes less fast. It is because the land needed for palm plantation become smaller, as shown in Figure 3. By applying scenario 3 , land area that need to be extended for palm plantation becomes smaller than the area in the existing condition as well as the area in scenarios 1 and 2. It affects the percentage of utilization of production forest area for palm plantation. This condition is described by the slope of curves of each scenario. Graphically, the slope of scenario 1 is the smallest among the others. It means that the development of palm plantation and the decrease of forest width in scenario 1 is the smallest among the others. The width of production forest is still sufficient, almost half of current condition untill the next 30 years. It differs from the availability of production forest in the existing condition and in the other scenarios, where production forest keeps on decreasing on the next 15-20 years. From these, we found that the decrease of production forest because of the shifting function into palm plantation may influence forest width's protection.

The decreasing rate of production forest is shown by gradients $\alpha^{0}, \alpha^{1}, \alpha^{2}$, and $\alpha^{3}$, where $\alpha^{0}=$ existing condition, $\alpha^{1}=$ scenario $1, \alpha^{2}=$ scenario 2 , and $\alpha^{3}=$ scenario 3 (Figure 3). Graphically, gradient $\alpha^{2}<\alpha^{0}<$ $\alpha^{1}<\alpha^{3}$ describes the sequence of the decreasing rate

Figure 4. Forest Deforestation

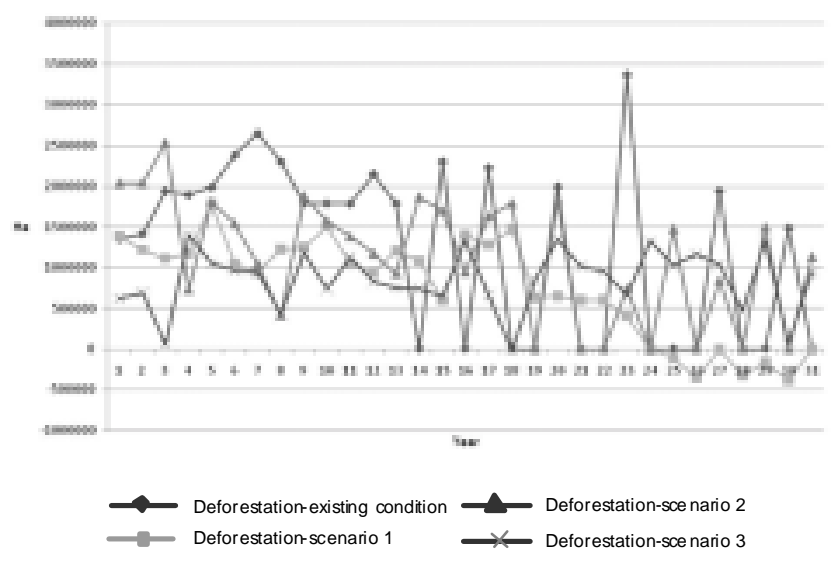


of the production forest width. The fastest is scenario 2 , and then followed by the existing condition, scenario 1 , and scenario 3 . Since the $7^{\text {th }}$ year, however, there is a shift on the sequence between scenario 2 and existing condition so that $\alpha^{0}<\alpha^{2}<\alpha^{1}<\alpha^{3}$.

On the other hand, the increasing rate of palm plantation width is shown by gradient $\beta^{0}, \beta^{1}, \beta^{2}$, and $\beta^{3}$, where $\beta^{0}=$ existing condition, $\beta^{1}=$ scenario 1 , $\beta^{2}=$ scenario 2 , and $\beta^{3}=$ scenario 3 . Figure 3 shows that graphically we obtained $\beta^{2}<\beta^{0}<\beta^{3}<\beta^{1}$. It illustrates the sequence of the increasing rate of palm plantation width, where the fastest is scenario 2, and followed by existing condition, scenario 3 , and scenario 1 . Starting from the $6^{\text {th }}$ year, however, the sequence is changed and it becomes $\beta^{0}<\beta^{2}<\beta^{1}<\beta^{3}$. During the simulation, the increase of palm plantation in scenario 1 is the most constant than the others, so at the end of period, the sequence becomes $\beta^{1}<\beta^{0}<\beta^{2}<\beta^{3}$.

To control deforestation, developing a better forest management to guarantee the raw material supply for industry (scenario 1) and increasing palm plantation productivity (scenario 3 ), as shown by Figure 4, are essential. Some values (at year 25, 26, 29 and 30) drop into a negative level by applying scenario 1 . Negative value means that deforestation would not be done anymore and the forest area would be increasing.

\subsection{Industry revenue}

Economic aspect generally becomes the main reference to review the development and the performance of industry. Economic aspect can be perceived from many sides. In this research, economic aspect is perceived as industry's income or revenue obtained from the furniture product sales.

It is difficult to observe the information of each scenario behavior based on the curve, because the curve does not show the specific pattern clearly. Hence, the increase or the improvement of industry revenue can be seen from the curve gradient. Figure 5a shows that $\mathrm{CPO}$ industry revenue in the existing condition and in scenario 3 tends to raise with gradient $9 \times 10^{6}$ and $3 \times 10^{6}$, respectively, while in scenario 1 and scenario 2 the industry revenue tends to decrease with gradient $9 \times 10^{6}$ and $1 \times 10^{6}$, respectively.

In furniture industry, the improvement of raw material supply management and the increase of production capacity do not give significant
Figure 5. Furniture and CPO Revenue

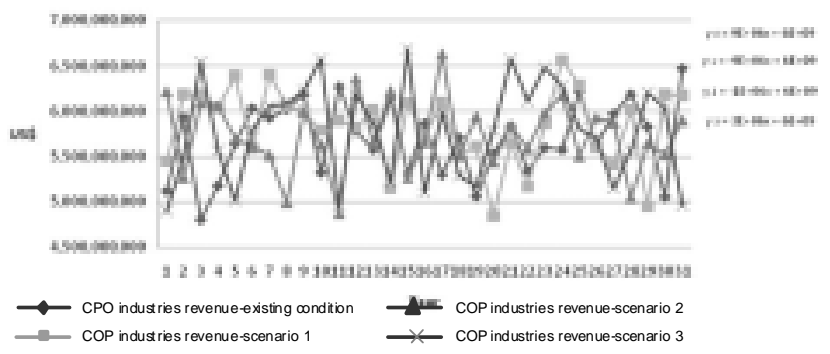

(a)

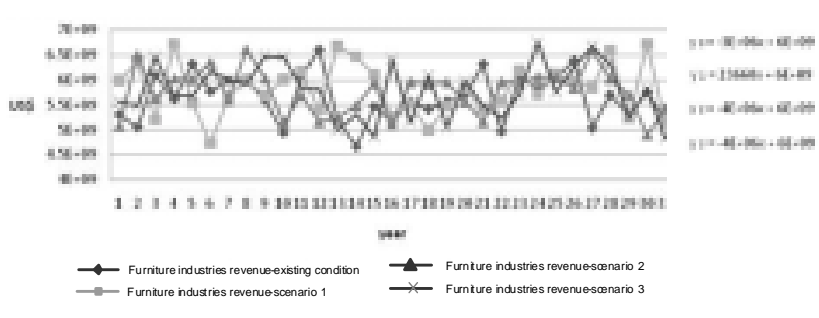

(b)

contribution to the industry's revenue. It may occur because of the undeveloped market condition or consumer. Within almost all of the scenarios, furniture industry revenue is decreasing, except for scenario 1 in which the revenue slightly increase. The decrease of furniture industry revenue can be seen from the curve gradient of Figure $5 \mathrm{~b}$. The gradient of existing condition, scenario 3 , and scenario 2 are $3 \times 10^{6}, 4 \times 10^{6}$, and $4 \times 10^{6}$, respectively. Meanwhile, scenario 1 is 23,660 , which is relatively constant.

\subsection{Labor absorption}

The development of palm plantations affects labor absorption as shown in Figure 6. We found that the biggest labor absorption occurs in scenario 1 with gradient $1 \times 10^{6}$. This is bigger than the current condition in which the gradient is $8.6 \times 10^{4}$. As the increase of palm plantation productivity in scenario 3 with the gradient is $5.98 \times 10^{3}$, labor absorption in this scenario is the smallest among the others.

The increasing rate of labor absorption in palm plantation from year 10 to 30 is shown in the Table 2 .

From Table 2, we found that the biggest rate of labor absorption from year 10 to 30 can be achieved if we implement scenario 1 . It is because the 
Figre 6. Labor Absorption in Palm Plantation

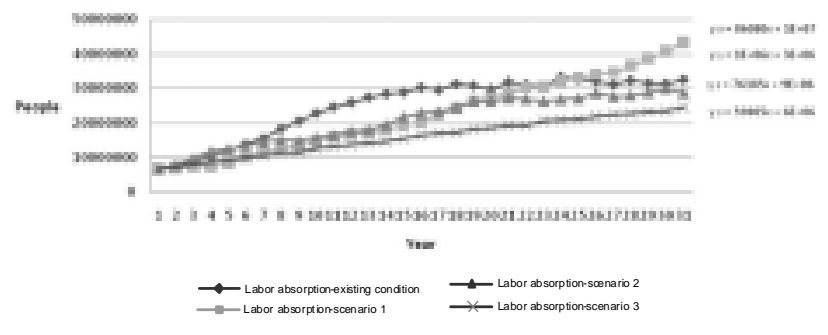

Table 2 Increasing rate of labor absorption

\begin{tabular}{|c|c|c|c|c|}
\hline \multirow{2}{*}{ Year } & \multicolumn{4}{|c|}{ Increasing rate of labor absontion } \\
\cline { 2 - 5 } & $\begin{array}{c}\text { Existing } \\
\text { condition }\end{array}$ & Scenario 1 & Scenario 2 & Scenario 3 \\
\hline $10-20$ & $7.92 \%$ & $76.9 \%$ & $8.2 \%$ & $8.65 \%$ \\
\hline $20-30$ & $7.34 \%$ & $43.17 \%$ & $7.23 \%$ & $8.21 \%$ \\
\hline
\end{tabular}

increasing rate of palm plantation width in scenario 1 is higher than those of the existing condition, scenario 2 and scenario 3 . The rate of labor absorption is linier to the increasing rate of palm plantation width.

The lowest rate of labor absorption in period 1020 is obtained within existing condition. It occurs because the increasing rate of palm plantation width in the existing condition is smaller than within scenario 1, 2, and 3. In years 20-30, however, the lowest rate of labor absorption is found in scenario 2 because in this period the increasing rate of palm plantation width is the smallest.

\section{Conclusion and Future Research}

The productivity of increasing palm plantations affects the optimization of the trade-off between the supply chain of furniture and $\mathrm{CPO}$ industries. It may decrease the conversion of natural production forest to palm plantation by reducing the rate of forest deforestation. On the other hand, however, the need of opening new palm plantations will decrease so that labor absorption at the plantation will also decrease.

A good forest management which guarantees the availability of wood as a raw material for industries may contribute to prevent the decrease of production forest area. The availability of wood supply can reduce illegal wood demand as one of the factors which contributes to deforestation.

From the simulation of the scenarios using the modified dynamic model, we found scenario 3 as the best one. This scenario can optimize the tradeoff between the supply chain of furniture and CPO industries in line with long term sustainable development. The scenario is set by increasing the productivity of palm plantations to change the pattern from extension to intensification by using robust palm plants.

In future research, we can consider more parameters for elaborating the 3 aspects in sustainable supply chain perspective in a more detailed way. The scope can be expanded, not only furniture and CPO industries but also other forest industries.

\section{Acknowledgment}

Author would like to express the deepest gratitude to Mr. Kharis Pramudya Dwi Arbita and Mr. Aang Abdullah for their valuable work to support this research.

\section{References}

Beamon, B.M. (2008). Sustainability and future of supply chain management. Journal Operations and Supply Chain Management 1(1), pp. 4-18.

Boulanger, P. and Bre'chet, T. (2005). Models for policymaking in sustainable development: The state of the art and perspectives for research. Ecological Economics 55, pp. 337-350.

Bovea, M.D., and Vidal, R. (2004). Materials selection for sustainable product design: a case study of wood based furniture eco-design. Materials and Design 25, pp. 111-116.

De Lara, M., and Martinet, V. (2009). Multi-criteria dynamic decision under uncertainty: A stochastic viability analysis and an application to sustainable fishery management. Journal Mathematical Biosciences 217, pp. 118-124.

Eltayeb, T. K, and Zailani. S. (2009). Going green through green supply chain initiatives towards environmental sustainability. Journal Operations and Supply Chain Management 2(2), pp. 93-110.

Fleisch, E. and Tellkamp, C. (2005). Inventory inaccuracy and supply chain performance: a simulation study of a retail supply chain. International Journal of Production Economics 95, pp. 373-385. 
Hadiguna, R, A, and Machfud. (2008). Production planning model of crude palm oil supply chain considering decision making preference. Industrial Engineering Journal 10(1), pp. 38-49.

Min, H. and Zhou, G. (2002). Supply chain modelling: past, present, and future. Computers $\mathcal{E}$ Industrial Engineering 43, pp. 231-249.

Jammernegga, W. and Reiner, G. (2007). Performance improvement of supply chain processes by coordinated inventory and capacity management. International Journal of Production Economics 108, pp. 183-190.

Johar, S., Tanjung, H., and Cahyadi, E.R. (2003). Building competitive advantage on CPO through SCM. Journal Agrobisnis dan Manajemen 1(1), pp. 20 - 32.

Kishor, Nalin, and Arati Belle. (2004). “Does improved governance contribute to sustainable forest management?" Co-published simultaneously in Journal of Sustainable Forestry 19(1/2/3), pp. 55-79.

Lau, R.S.M., Xie, J., and Zhao, X. (2008). Effects of inventory policy on supply chain performance: A simulation study of critical decision parameters. Computers $\mathcal{E}$ Industrial Engineering 55, pp. 620-633.

Lee, Y.H., Cho, M.K., Kim, S.J., and Kim, Y,B. (2002). Supply chain simulation with discrete-continuous combined modelling. Computers $\mathcal{E}$ Industrial Engineering 43, pp. 375-392.

Lin, S.S, and Juang, Y.S. (2008). Selecting green suppliers with analytic hierarchy process for biotechnology industry. Journal Operations and Supply Chain Management 1(2), pp. 115-129.

Linton, J.D., Klassen, R., and Jayaraman, V. (2007). Sustainable supply chain: An introduction. Journal of Operation Management 25, pp. 1075-1082.

Longo, F. and Mirabelli, G. (2008). An advanced supply chain management tool based on modeling and simulation. Computers $\mathcal{E}$ Industrial Engineering 54, pp. 570-588

Ortiz, O., Francesc, C., and Guidi, S. (2009). Sustainability in the construction industry, a review of recent developments based on LCA. Journal of Construction and Building Materials 23, pp. 28-39.

Palm and palm oil (development of palm plantation area and palm oil production). (2008). Directorate General of Estate Crops, Ministry of Agriculture Republic of Indonesia.
Pierreval, H., Bruniaux, R. and Caux, C. (2007). A continuous simulation approach for supply chains in the automotive industry. Simulation Modelling Practice and Theory 15, pp. 185-198.

Robb, D.J., Xie, B., and Arthanari, T. (2008). Supply chain and operations practice and performance in Chinese furniture manufacturing. International Journal of Production Economics 112, pp. 683-699.

Schwartz, J.D., Wang, W. and Rivera, D.E. (2006). Simulation-based optimization of process control policies for inventory management in supply chains. Automatica 42, pp. 1311 - 1320.

Tambunan, T. (2006). The development and the competitiveness of Indonesian wooden furniture export. www.kadin-indonesia.or.id.

Terzi, S. and Cavalieri, S. (2004). Simulation in the supply chain context: a survey. Computers in Industry 53, pp. 3-16.

The Report of Industry Sector Development. (2008). The Ministry of Industry Republic of Indonesia.

Vickery, S.K., Dröge, C., and Markland, R.E. (1997). Dimensions of manufacturing strength in the furniture industri. Journal of Operations Management 15, pp. 317-330.

Widodo, K.H., Abdullah, A., and Arbita, K.P.D. (2009a). "System analysis for supply chain of CPO in Indonesia with considering profit, social welfare and environmental aspect". Industrial Engineering Journal 12 (1), pp. 47-54.

Widodo, K.H., Arbita, K.P.D, and Abdullah, A. (2009b). "Identification of furniture industry system from sustainable supply chain management perspective". Agritech 30 (2), pp. 107-115

Widodo, K.H., Arbita, K.P.D, and Abdullah, A. (2009c). Dynamic model for analyzing trade-off between furniture and crude palm oil industry to build a sustainable supply chain. Proceeding of The $11^{\text {th }}$ International Conference on QiR (Quality in Research), Depok, Indonesia, pp. F2-S4-3.

Widodo, K.H., Kusuma, P.T.W.W., and Arbita, K.P.D. (2009d). Cassava agroindustry development based on sustainable supply chain perspective. Proceeding of Seminar on Application and Research in Industrial Technology (SMART), Yogyakarta, Indonesia, pp. B-001 - B-006.

Kuncoro Harto Widodo is Associate Professor of Logistics and Supply Chain Management, Department of Agriculture Industrial Technology, Faculty of Agricultural Technology and Director of Center for Transportation and Logistics Studies at Universitas Gadjah Mada, Yogyakarta, Indonesia. He holds a bachelor's degree from Universitas Gadjah Mada and he earned his master's degree and doctorate at Osaka Prefecture University, Japan. Dr. Kuncoro has published over 25 publications including articles and proceedings papers that have appeared in a wide variety of logistics and supply chain management and operations management. 